\title{
LA PESCA MARÍTIMA RECREATIVA: EN EL MARCO DE LA POLITICA PESQUERA COMÚN
}

\section{MARITIME RECREATIONAL FISHERIES: IN THE FRAMEWORK OF THE COMMON FISHERIES POLICY}

\author{
MARÍA GimÉnEZ CASALDUERO \\ Profesora Asociada de Derecho Administrativo \\ Universidad de Murcia / Universidad de Alicante \\ mariagim@um.es / maria.gimenez@ua.es
}

Fecha de recepción: 25 de febrero de 2021 / Fecha de aceptación: 16 de abril de 2021

RESUMEN: En las últimas décadas, el fenómeno de la pesca marítima de recreo ha experimentado un crecimiento notable a nivel mundial. En el ámbito de la Unión Europea resulta imprescindible avanzar en herramientas específicas de gestión que permitan optimizar la potencialidad socioeconómica del sector recreativo. Hasta el momento, el control público sobre las pesquerías recreativas se ha llevado a cabo a través de los registros de licencias y autorizaciones. No obstante, la existencia de un marco legal disperso, en cuanto a la regulación de los instrumentos jurídicos de intervención sobre la pesca está impidiendo la obtención de datos precisos en el área. Este escenario pone al descubierto la importancia de elaborar un marco jurídico común para la pesca recreativa a escala europea y específicamente a nivel de cuencas marítimas. Para ello, la puesta en marcha de los principios de nueva gobernanza -en concreto, el relativo al enfoque regionalizado de gestión y el de fomento de la participación de todos los "grupos interesados" en los asuntos de la pesca-, no solo facilitarían la mejora en la recopilación de datos, sino que, además, permitirían avanzar en el reconocimiento del sector recreativo en el marco de la política pesquera común y la gestión sostenible de las pesquerías recreativas de cara a 
la implementación de los instrumentos de la Política marítima integrada de la Unión Europea.

RESUM: En les últimes dècades, el fenomen de la pesca marítima recreativa ha experimentat un creixement notable a nivell mundial. En l'àmbit de la Unió europea resulta imprescindible avançar en eines específiques de gestió que permetin optimitzar la potencialitat socioeconòmica de el sector recreatiu. Fins al moment, el control públic sobre les pesqueres recreatives s'ha dut a terme a través dels registres de llicències i autoritzacions. No obstant això, l'existència d'un marc legal dispers, pel que fa a la regulació dels instruments jurídics d'intervenció sobre la pesca està impedint l'obtenció de dades precises a l'àrea. Aquest escenari posa a l'descobert la importància d'elaborar un marc jurídic comú per a la pesca recreativa a escala europea i específicament a nivell de conques marítimes. Per a això, la posada en marxa dels principis de nova governança —en concret, el relatiu a l'enfocament regionalitzat de gestió basat en la Conca marina, i el foment de la participació de tots els "grups interessats" en els assumptes de la pesca-, no només facilitarien la millora en la recopilació de dades, sinó que, a més, permetrien avançar en el reconeixement ple de el sector recreatiu en el marc de la política pesquera comuna i la gestió sostenible de les pesqueries recreatives de cara a la implementació dels instruments de la Política marítima integrada de la Unió Europea.

ABSTRACT: In recent decades, the phenomenon of marine recreational fisheries has experienced remarkable growth worldwide. Within the European Union, it is essential to advance in specific management tools that allow optimizing the socio-economic potential of the recreational sector. So far, public control over recreational fisheries has been carried out through the registers of licenses and authorizations. However, the existence of a dispersed legal framework regarding the regulation of the legal instruments of intervention on fishing is preventing the obtaining of precise data in the area. This scenario reveals the importance of developing a common legal framework for recreational fisheries on a European and specifically at the level of sea basins. To this end, the implementation of the new governance principles - specifically, the regionalized approach to management based on the marine basin, and the promotion of the participation of all "interested groups" in fisheries matters-, not 
only would it facilitate improvement in data collection, but would also allow progress in the full recognition of the recreational sector within the framework of the Common Fisheries Policy and facilitate the sustainable management of recreational fisheries with a view to the implementation of the instruments of the Integrated Maritime Policy of the European Union.

PALABRAS CLAVE: Pesca marítima de recreo - Política pesquera común Regionalización - Participación - Ordenación del espacio marítimo.

PARAULES CLAU: Pesca marítima de recreació - Política pesquera comuna Regionalització - Participació - Ordenació espai marítim.

KEYWORDS: Marine recreational fisheries - Common fisheries policy Regionalization - Participation - Maritime spatial planning.

SUMARIO: I. INTRODUCCIÓN. II. IMPLICACIONES AMBIENTALES DE LA PESCA MARÍTIMA DE RECREO. III. REGULACIÓN SECTORIAL DE LA PESCA RECREATIVA EUROPEA: UN MARCO JURÍDICO INSUFICIENTE. 1. El régimen de control de la política pesquera común. 2. Recopilación y accesibilidad a los datos del sector pesquero recreativo: una tarea pendiente. 3. Las posibilidades de capturas recreativas en aguas de la Unión. 4. Vertiente financiera de la política pesquera común. IV. ELEMENTOS VERTEBRADORES PARA LA INTEGRACIÓN EFECTIVA DE LA PESCA RECREATIVA EN LA POLÍTICA PESQUERA DE LA UE. 1. Importancia de la adecuada ordenación de usos en el espacio marítimo. 2. Aplicación del enfoque regional de gestión pesquera a la pesca marítima de recreo. 3 . El fomento de la participación en la gestión de las pesquerías recreativas. V. CONCLUSIONES. VI. BIBLIOGRAFÍA.

\section{INTRODUCCIÓN}

El fenómeno de la pesca recreativa ha experimentado un crecimiento notable en las últimas décadas. Estimaciones recientes calculan que en la mayoría de países desarrollados una de cada diez personas pesca por placer, lo que se traduce en 220 millones de pescadores recreativos en todo el mundo, más de cuatro veces el número de pescadores de captura comercial ${ }^{1}$.

EI Consejo Internacional para la Exploración del Mar (CIEM o ICES por sus siglas en inglés) ${ }^{2}$ define la pesca marítima recreativa (en adelante PMR) como la

\footnotetext{
${ }^{1}$ Robert Arlinghaus, Joshua K. Abbott, Eli P. Fenichel, ...et al., "Governing the recreational dimension of global fisheries", PNAS, vol. 116, oㅡ 12, 2019, p. 5209.

2 EI CIEM es una organización intergubernamental de ciencias marinas que responde a las necesidades de la sociedad de disponer de datos imparciales sobre el estado y el uso sostenible de los mares y océanos. A través de asociaciones estratégicas, su trabajo se extiende al Océano Atlántico, al Ártico, el Mar Mediterráneo, el Mar Negro y el Océano Pacífico Norte.
} 
captura o intento de captura de recursos acuáticos vivos principalmente para el ocio o el consumo personal ${ }^{3}$. Acorde con esta definición, el Real Decreto $347 / 2011$, de 11 de marzo, por el que se regula la pesca marítima de recreo en aguas exteriores españolas la describe como aquella "actividad pesquera no comercial que explota los recursos acuáticos vivos con fines recreativos de ocio, prohibiéndose la venta o transacción de las capturas obtenidas" (artículo 1). ${ }^{4}$

Según su conceptualización, la pesca marítima recreativa —en contraste con la pesca comercial o la de subsistencia- se fundamenta en la prohibición de vender las capturas, la falta de profesionalidad del sujeto que la practica y la finalidad lúdica que persigue $;^{5} \mathrm{y}$, en el caso que su práctica se desarrolle en el seno de una actividad deportiva, la competición pasaría a ser su finalidad esencial. A pesar de que la PMR excluye el ánimo de lucro entre sus objetivos, recientes estudios científicos la califican como una actividad pesquera de gran peso económico que aglutina a casi 9 millones de practicantes en aguas de la Unión Europea (UE) -1.6\% de la población-que generan un gasto de 6.000

\footnotetext{
<https://www.ices.dk/Pages/default.aspx> [Última consulta, 31 de mayo de 2021].

${ }^{3}$ En dicha definición se entienden incorporados los artes de pesca activos, entre los que figura la pesca con líneas, arpones y la pesca a mano; y pasivos, como las redes, trampas, nasas y palangres. ICES, Report of the Working Group on Recreational Fisheries Surveys (WGRFS), ICES CM 2013/ACOM:23, 2013, p.2.
}

\footnotetext{
${ }^{4}$ Real Decreto 347/2011, de 11 de marzo, por el que se regula la pesca marítima de recreo en aguas exteriores españolas, publicado en el BOE n. 81 , de 5 de abril de 2011. En fechas recientes, marzo del 2021, la Dirección General de Pesca Sostenible del Ministerio de Agricultura, Pesca y Alimentación ha presentado un borrador de reforma del Real Decreto $347 / 2011$ sobre pesca marítima de recreo en aguas exteriores españolas que actualmente se encuentra en trámite de información pública. Borrador disponible en $<$ https://www.mapa.gob.es/es/pesca/participacion-publica/> [Última consulta, 31 de mayo de 2021].

${ }^{5}$ Se entiende por "pesca comercial" la actividad pesquera llevada a cabo de manera profesional, tanto a tiempo completo como parcial, destinada a la captura de peces y otros organismos acuáticos, con el fin de satisfacer necesidades humanas nutricionales (esenciales) por medio de la venta en mercados internos y de exportación. Esta categoría comercial incluye asimismo las pesquerías que suministran recursos pesqueros a sectores como la acuicultura y la agricultura (piensos), y sirven de materias primas a otros sectores industriales como, por ejemplo, el de la biomedicina. Por su parte, la "pesca de subsistencia" se podría definir como la captura de animales acuáticos orientada a cubrir las necesidades nutricionales de una persona sin intervención del mercado, destinándose los productos obtenidos de la pesca al consumo propio del pescador o de su entorno más cercano de familiares y amigos. FAO, Recreational fisheries. Technical Guidelines for Responsible Fisheries, no. 13, Rome, 2012, p. 3. Por su parte, Ignacio Arroyo distingue la pesca recreativa en oposición a la pesca profesional, en cuanto carece de los elementos de habitualidad y ánimo de lucro, "Debe ser, por tanto, ocasional o esporádica y no perseguir una finalidad económica, aunque no la desnaturaliza el hecho de emplear una embarcación que se explota comercialmente", en Ignacio Arroyo Martínez, Compendio de Derecho Marítimo, 3를 Ed, Tecnos, Madrid, 2009, p. 217.
} 
millones de euros anuales aproximadamente para el desarrollo de la actividad. ${ }^{6}$ Solo en las costas españolas operan cerca de 300.000 pescadores recreativos con un gasto directo de 217 millones $€$ anuales. ${ }^{7}$ Esta cifra puede llegar a sobrepasar el valor añadido de la pesca profesional según las zonas ${ }^{8}$. Por otra parte, en cuanto a la generación de empleo, algunas evaluaciones vinculan al sector de la PMR con la creación de 10.000 puestos de trabajo en toda Europa relacionados con el turismo, la producción, venta y alquiler de equipamiento y demás servicios auxiliares de la pesca ${ }^{9}$.

A la luz de estos datos, la necesidad de establecer un marco jurídico común sobre determinados aspectos de la pesca recreativa a nivel de la Unión Europea podría ayudar a optimizar las potencialidades socioeconómicas del sector. Hasta el momento, los instrumentos más efectivos para evaluar el fenómeno de la PMR han sido los registros de las licencias o autorizaciones emitidas conforme a las exigencias del ordenamiento jurídico de cada país. Lamentablemente, la existencia de un marco legal disperso en cuanto a la emisión de licencias ha dificultado la obtención de datos fiables para la mejora de la gestión del sector

\footnotetext{
${ }^{6}$ Pablo Pita, Josep Alós, Manel Antelo, et al., "Estado del arte de la investigación sobre pesca marítima recreativa en España", en Pablo Pita, Sebastián Villasante (Eds.): Informe técnico del Proyecto SICORE. 2018, Santiago de Compostela, España, p. 4; y, Kieran Hyder, Marc Simon Weltersbach, Mike Armstrong, et al., "Recreational sea fishing in Europe in a global context. Participation rates, fishing effort, expenditure, and implications for monitoring and assessment", Fish Fish, 2018, p.7.

7 Este número de pescadores recreativos corresponde en una mayor proporción a los que practican la actividad desde embarcación, modalidad que requiere un gasto directo más elevado debido al coste de la compra, el mantenimiento y el amarre de las embarcaciones, así como los gastos relacionados con el transporte y el alojamiento. Toni Font, Josep Lloret, Catherine Piante, Recreational Fishing Within Marine Protected Areas in the Mediterranean Marine Protected Areas in the Mediterranean, Technical Report, MedPAN North Project, WWF France, 2012.
}

${ }^{8}$ En el litoral mediterráneo español existen diferencias importantes entre zonas. Por ejemplo, provincias como Almería, Cádiz, Granada, Tarragona, Alicante y Castellón mantienen un claro dominio de la pesca profesional; sin embargo, en Barcelona, Illes Balears, Girona y Málaga la pesca marítima de recreo genera hasta cuatro veces más valor añadido que la pesca profesional. TRAGSATEC, Estudio del impacto socioeconómico de la pesca recreativa en el Mediterráneo Español, Secretaría General de Pesca Marítima, Ministerio de Agricultura, Pesca y Alimentación, Madrid, versión actualizada 2010, p. 100.

${ }^{9}$ La creación de puestos trabajo presenta ciertas variaciones entre regiones marítimas, por ejemplo, el Mar del Norte se configura como el mayor contribuyente global de empleo, seguido del Atlántico Noroccidental, el Mediterráneo, el Atlántico Sudoccidental y el Mar Báltico, posicionado con la menor contribución el Mar Negro. Silvia Gómez, Arnau Carreño, Elvira Sánchez, Esther Martínez, Josep Lloret, Safeguarding Marine Protected Areas in the growing Mediterranean Blue Economy. Recommendations for Recreational Fisheries. PHAROS4 MPAs project, 2019, p.22. 
recreativo, especialmente en países del área mediterránea como Francia, Italia y España ${ }^{10}$.

Precisamente, en el año 2019, una Resolución del Parlamento Europeo (en adelante PE) basada en las recomendaciones de la Comisión de Pesca recordaba que, entre los objetivos fijados en la Declaración Ministerial MedFish4Ever (Declaración de Malta) ${ }^{11}$ _adoptada en marzo de 2017 por todos los Estados costeros del Mediterráneo con la finalidad de implantar un plan de acción para la cooperación y el desarrollo sostenible de la pesca en los próximos diez años - se exigía el establecimiento de un conjunto de normas de referencia para garantizar una gestión eficaz de la pesca recreativa en el Mediterráneo de cara al año $2020 .{ }^{12}$

En consonancia con ese objetivo, la Estrategia 2017-2020 de la Comisión General de Pesca del Mediterráneo (CGPM) ha incluido, entre las acciones a llevar a cabo en la zona, la evaluación del impacto de la pesca recreativa y la consideración de las mejores medidas de gestión para regular esta actividad. Con el compromiso de llevar a cabo esta tarea, la CGPM ha creado un grupo de trabajo para la pesca recreativa con el fin de elaborar una metodología regional armonizada para la evaluación de esta modalidad de pesca ${ }^{13}$.

\section{IMPLICACIONES AMBIENTALES DE LA PESCA MARÍTIMA DE RECREO}

La pesca profesional de carácter comercial ha sido siempre considerada como la principal causante de la disminución global de las pesquerías; sin embargo, el

\footnotetext{
${ }^{10}$ Ana Gordoa (Coord.) SFITUM Project: Sport Fishing: an informative and economic alternative for Tuna fishing in the Mediterranean, DG Fish. 2003, págs. 82 y ss.

${ }^{11}$ Declaración Ministerial MedFish4Ever. $<$ https://www.actu-environnement.com/media/pdf/news-28756-declaration-malte-surpechemediterranee.pdf $>$ [Última consulta, 31 de mayo de 2021].

12 Parlamento Europeo, Resolución legislativa de 26 de marzo de 2019, sobre la propuesta de Reglamento del Parlamento Europeo y del Consejo por el que se modifica el Reglamento (UE) 1343/2011, sobre determinadas disposiciones aplicables a la pesca en la zona del Acuerdo CGPM (Comisión General de Pesca del Mediterráneo), (COM (2018) 0143 - C8-0123/2018 2018/0069 (COD)).

$<$ https://www.europarl.europa.eu/doceo/document/TA-8-2019-0234 ES.pdf> [Última consulta, 31 de mayo de 2021].

${ }^{13}$ GFCM. Report of the first meeting of the Working Group on Small-Scale and Recreational Fisheries (WGSSF). FAO, Rome, 2017. <http://www.fao.org/gfcm/technicalmeetings/detail/en/c/1061844/> [Última consulta, 31 de mayo de 2021].
} 
espectacular incremento de las actividades relacionadas con la PMR exige tomar en serio sus impactos.

Aunque los pescadores con caña ejercen menor presión que los pescadores industriales sobre las poblaciones de peces y los ecosistemas de los que forman parte, en fechas recientes, el sector científico aboga por considerar la explotación recreativa de los recursos en pie de igualdad con la pesca comercial, especialmente en el caso de las pesquerías costeras de carácter mixto en las que confluyen la pesca comercial y la de recreo ${ }^{14}$. Este problema se acrecienta ante la ausencia de una regulación adecuada que evitaría convertir a la PMR en una suerte de caja negra donde se enmascaran de recreativa capturas ilegales, no declaradas y no reglamentadas (INDNR). Precisamente, para prevenir la pesca INDNR, los impactos sobre el medio marino y sus recursos o los conflictos de acceso entre sectores, se viene demandando la integración de los datos relativos a la PMR en el grueso de las estimaciones de las capturas pesqueras totales, pues, en caso contrario, se corre el riesgo de provocar un asesoramiento incorrecto sobre la ordenación de la pesca.

Diversos autores distinguen entre los impactos directos que se producen sobre las especies objetivo ${ }^{15}$, y los indirectos, aquellos que afectan a otros componentes del ecosistema derivados del ejercicio de la actividad pesquera. En cuanto a las especies capturadas por la PMR y que son objetivo también de la pesca comercial a pequeña escala (tiburones, rayas, etc.) ${ }^{16}$-, pueden llegar a alcanzar una situación crítica a pesar de estar catalogadas como vulnerables por el Convenio de Barcelona (1976), el Convenio de Berna (1979), el Convenio

\footnotetext{
${ }^{14}$ Robert Arlinghaus, et al., "Governing the recreational dimension..., cit. p.5209.

${ }^{15}$ En cuanto a los impactos directos, la presión de la pesca marítima de recreo sobre los recursos pesqueros incide de manera relevante sobre determinadas zonas del Mediterráneo. En el Parque Natural de Cabo de Creus (Gerona) las capturas de PMR representan cerca del 50\% de las capturas totales en el área. Toni Font y Josep LLoret, Análisis de la pesca de recreo en las 10 Áreas LIC del proyecto LIFE+INDEMARES, Universidad de Girona - Ministerio de Agricultura, Alimentación y Medio Ambiente - Fundación Biodiversidad, 2013, p.55.

${ }^{16}$ El riesgo sobre algunas especies "vulnerables" se acrecienta con el incremento de la actividad de la PMR, muy significativo en las costas italianas, españolas y francesas. En el caso de España sería relativamente fácil de detectar el impacto real que ejerce la PMR sobre especies sujetas a protección específica mediante la contabilización del número de barcos de recreo con autorización especial para la pesca de grandes peces pelágicos, según el artículo 10 del Real Decreto 347/2011, de 11 de marzo, por el que se regula la pesca marítima de recreo en aguas exteriores. Josep LLoret, Victoria Riera, "Evolution of a Mediterranean Coastal Zone: Human Impacts on the Marine Environment of Cape Creus", Env. Manag, №. 42, 2008, p.985.
} 
CITES (1973), la Lista Roja de Especies Amenazadas de la Unión Internacional para la Conservación de la Naturaleza (IUCN) o la Directiva Hábitats de la Unión Europea (UE).

Por otra parte, como señala la Comisión Europea, alrededor del $20 \%$ de los aparejos de pesca utilizados por los pescadores se pierden en el mar, pudiendo llegar a ocasionar graves daños a los ecosistemas marinos. ${ }^{17}$ Lamentablemente, en el caso de los aparejos de pesca recreativa (sedal, redes, anzuelos, plomos, etc.), el ordenamiento jurídico no se ha ocupado de regular los materiales que deben ser utilizados, ni qué tipo de actuación se debería emprender ante los efectos de su pérdida en el mar.

Otra cuestión extremadamente delicada para la protección de los hábitats marinos y relacionada con la pérdida de biodiversidad es la relativa al uso de especies alóctonas (no nativas) como cebo para pescar recreativamente ${ }^{18}$. En el caso de la laguna costera del Mar Menor —ubicada en el Mediterráneo occidental y considerada zona protegida en base a múltiples categorías jurídicos a escala internacional, europea, nacional y regional-, se ha detectado, por primera vez, la existencia de una especie exótica fuera de su rango de distribución natural (Pacífico noroccidental), —el gusano (Perinereis linea)—que llegó al Mar Menor a través de un cebo vivo importado y comúnmente utilizado por los pescadores recreativos en la laguna.

Pero sin duda, uno de los impactos indirectos más dañinos para los ecosistemas marinos se produce mediante el fondeo de las embarcaciones. El fondeo afecta a especialmente a las praderas de posidonia (Posidonia oceanica), hábitat

17 European Commission. New proposal will tackle marine litter and "ghost fishing, 2018. $<$ https://ec.europa.eu/fisheries/new-proposal-will-tackle-marine-litter-and-"ghost-fishing" en> [Última visita, 31 de mayo de 2021]. Se debe señalar que el plomo (de las plomadas o pesas utilizadas por muchos pescadores) es muy tóxico cuando se disuelve en el agua. Además de afectar a los organismos marinos, puede acumularse a través de la cadena trófica hasta llegar a los seres humanos cuando consumen alimentos marinos.

${ }^{18}$ Robert J. DiStefano, Mary E. Litvan, Paul T. Horner, "The Bait Industry as a Potential Vector for Alien Crayfish Introductions: Problem Recognition by Fisheries Agencies and a Missouri Evaluation". Fisheries, № 34(12), 2009, p. 586; y, Víctor M. León, José M. Bellido (Eds.). "Mar Menor: una laguna singular y sensible. Evaluación científica de su estado", Instituto Español de Oceanografía, Ministerio de Economía y Competitividad, Madrid, Temas de Oceanografía. oㅡ 9, 2016, p. 168. 
vulnerable incluido en la Red Natura 2000 y de un alto valor ecológico, al igual que los fondos de coralígeno.

Fruto de la preocupación por el deterioro constante de los fondos marinos se viene reclamando una ordenación efectiva de la náutica recreativa, especialmente cuando se desenvuelve en áreas marinas protegidas o en zonas limítrofes. ${ }^{19}$ Una de las modalidades más frecuentes en la practica de la pesca recreativa es la de embarcación fondeada (pesca de fondo o brumeo), por ello, y con la finalidad de prevenir sus impactos en los fondos marinos, habitualmente los instrumentos de gestión de las AMPs exigen la instalación de boyas ecológicas o decretan la prohibición total o parcial del fondeo en el área.

En relación con la avifauna marina, una de las principales causas del declive de especies como las pardelas y las gaviotas es la captura accidental por el uso de determinadas artes de pesca profesional (palangres); si bien, algunos estudios ya han documentado casos de enganches de aves en los anzuelos y líneas procedentes de la pesca recreativa. ${ }^{20}$

En cuanto al cambio climático, obviamente sus efectos alcanzarán a todas las pesquerías mundiales, incluidas las recreativas. La PMR se verá afectada de manera similar a la pesca comercial ante los cambios relacionados con el área de distribución de determinadas especies, la aparición de especies alóctonas (exóticas o invasoras), la disminución de la abundancia de una población o la variación del tamaño corporal de los peces.

Como ha planteado en fechas recientes la Organización de las Naciones Unidas para la Alimentación y la Agricultura (FAO por sus siglas en inglés), si el cambio

19 Patrice Francour, Anne Ganteaume and Maxime Poulain, "Effects of boat anchoring in Posidonia oceanica seagrass beds in the Port-Cros National Park (NW Mediterranean Sea)". Aquatic Conservation: Marine and Freshwater Ecosystems, no 9,1999, p. 391-400; y, Charles Boudouresque, Guillaume Bernard, Gerard Pergent, Abdessalem Shili, Marc Verlaque, Regression of Mediterranean seagrasses caused by natural processes and anthropogenic disturbances and stress: a critical review, Botanica Marina 52: 395-418, 2009.

${ }^{20}$ Carles Carboneras, Las aves marinas en España. Interacciones con artes de pesca. Casos prácticos, en Curso sobre Conservación y Gestión de la Biodiversidad Marina en España. Vigo, 22-26, septiembre 2008. Ministerio de Medio Ambiente y Medio Rural y Marino. En ocasiones, los pescadores recreativos aprovechan los lugares donde las aves están alimentándose para pescarlos -por ejemplo, cuando las embarcaciones de arrastre llegan a puerto y descartan grandes cantidades de peces para evitar sanciones-, aumentando en estos casos el riesgo de pesca accidental de gaviotas o charranes que confunden los señuelos y cebos recreativos con su alimento. Lo mismo ocurre cuando se practica la pesca al curricán de superficie o el spinning. Toni Font y Josep Lloret, Análisis de la pesca de recreo..., cit., pág. 68. 
climático varía las oportunidades de captura de especies o poblaciones debido a cambios en su distribución espacial, los derechos de acceso a los recursos tendrán que adaptarse a las posibilidades de explotación en otros lugares y resolver los posibles problemas de asignación intersectorial que puedan surgir. ${ }^{21}$ En un escenario de cambio climático será más necesario que nunca que los gestores actúen teniendo en cuenta todos los sectores implicados, evaluando de manera precisa el estado ecológico que tendrán las especies en el futuro ecosistema.

\section{REGULACIÓN SECTORIAL DE LA PESCA RECREATIVA EUROPEA: UN MARCO JURÍDICO INSUFICIENTE}

Hasta la fecha, y a falta de su integración efectiva en el seno de la Política Pesquera Común (en adelante PPC), la PMR ha sido regulada a nivel europeo de manera sectorial por medio de diversos reglamentos. Los reglamentos son disposiciones normativas del Consejo y del Parlamento Europeo, extremadamente detalladas y con muy poca flexibilidad en su ejecución, que no siempre son capaces de llevar a cabo una aplicación sensible a las cuestiones locales. Presumiblemente, la elaboración por el Consejo y el Parlamento Europeo de principios comunes sobre PMR y su posterior delegación ejecutiva en los Estados miembros, en la Comisión o en la autogestión por parte del sector, permitiría que el sector asumiera un mayor grado de responsabilidad en la gestión sostenible de su actividad.

Al margen de la tímida referencia incluida en el Reglamento (UE) n. ${ }^{0} 1380 / 2013$ del Parlamento Europeo y del Consejo de 11 de diciembre sobre la PPC: "La pesca recreativa puede tener un impacto significativo en los recursos pesqueros, y por ello los Estados miembros deben asegurar que se realiza de forma compatible con los objetivos de la política pesquera común",22 la PMR adquiere protagonismo en otras normas jurídicas comunitarias de gran relevancia.

\footnotetext{
${ }^{21}$ Manuel Barange, Tarûb Bahri., Malcolm C.M. Beveridge, Kevern L. Cochrane, Simon FungeSmith, and Florence Poulain, "Impacts of Climate Change on Fisheries and Aquaculture: Synthesis of currrent knowledge, adaptation and mitigation options", Rome, FAO Fish, 2018, 627 p. 353.

${ }^{22}$ Considerando $3^{\circ}$ del Reglamento (UE) № 1380/2013 del Parlamento Europeo y del Consejo, de 11 de diciembre de 2013, sobre la Política Pesquera Común, por el que se modifican los
} 


\section{El régimen de control de la política pesquera común}

Con la finalidad de gestionar de un modo coherente los objetivos de la PPC desde el punto de vista ambiental, económico y social, la aplicación efectiva del régimen de control supone una garantía para el cumplimiento eficaz de sus postulados.

El bloque normativo de control de la pesca en la Unión está conformado por el Reglamento 1224/2009 que establece un régimen comunitario de control para garantizar el cumplimiento normativo de la PPC (en adelante Reglamento de control) ${ }^{23}$, el Reglamento de la Agencia Europea de Control de la Pesca (AECP) de $2019^{24}$, el Reglamento que establece un sistema comunitario para prevenir, desalentar y eliminar la pesca ilegal, no declarada y no reglamentada (Reglamento INDNR) de $2008^{25}$ y el Reglamento sobre la gestión sostenible de las flotas pesqueras exteriores de $2017^{26}$.

El Reglamento de control también reconoce a la pesca recreativa como un sector que puede ocasionar un impacto significativo en los recursos pesqueros ${ }^{27}$. En este sentido, la UE delega en los Estados miembros la función de asegurar la práctica recreativa de la pesca de forma compatible con los objetivos de la PPC.

Reglamentos (CE) no 1954/2003 y (CE) no 1224/2009 del Consejo, y se derogan los Reglamentos (CE) no 2371/2002 y (CE) no 639/2004 del Consejo y la Decisión 2004/585/CE del Consejo, publicado en el Diario Oficial de la Unión Europea, L 354, de 28 de diciembre de 2013, p. 22-61.

${ }^{23}$ Reglamento (CE) del Consejo n.o 1224/2009, de 20 de noviembre de 2009, por el que se establece un régimen comunitario de control para garantizar el cumplimiento de las normas de la política pesquera común, publicado en el Diario Oficial de la Unión Europea, L 343, de 22 de diciembre de 2009, p. 1-50.

${ }^{24}$ Reglamento (UE) n. $2019 / 473$ del Parlamento Europeo y del Consejo, de 19 de marzo de 2019, sobre la Agencia Europea de Control de la Pesca, publicado en el Diario Oficial de la Unión Europea, L 83, de 25 de marzo de 2019, p. 18-37.

${ }^{25}$ Reglamento (CE) n. .9 1005/2008 del Consejo, de 29 de septiembre de 2008, por el que se establece un sistema comunitario para prevenir, desalentar y eliminar la pesca ilegal, no declarada y no reglamentada, publicado en el Diario Oficial de la Unión Europea, L286, de 19 de octubre de 2008, p. 1-32; y Reglamento (CE) n.․ 1010/2009 de la Comisión, de 22 de octubre de 2009 que establece normas de desarrollo del Reglamento (CE) $n . .01005 / 2008$, publicado en el Diario Oficial de la Unión Europea, L 280, de 27 de octubre de 2009, p. 5-41.

${ }^{26}$ Reglamento (UE) n.․ 2017/2403 del Parlamento Europeo y del Consejo, de 12 de diciembre de 2017, sobre la gestión sostenible de las flotas pesqueras exteriores, publicado en el Diario Oficial de la Unión Europea, L 347, de 28 de diciembre de 2017, p. 81-104.

${ }^{27}$ Considerando 27 del Reglamento (CE) del Consejo n.. $1224 / 2009$, de control. 
Ahora bien, en caso de un impacto relevante el Consejo podrá intervenir para establecer medidas específicas de gestión. De esta manera, la responsabilidad estatal de velar por una pesca recreativa sostenible en aguas comunitarias ha impedido, hasta cierto punto, el desarrollo de una regulación común en el seno de la Unión.

Adicionalmente, en virtud del artículo 55 del Reglamento 1224/2009, los Estados miembros deben recoger los datos de las capturas de la pesca recreativa sobre aquellas poblaciones sujetas a planes de recuperación, excluyendo explícitamente la pesca realizada desde la costa. No obstante, si el Comité Científico, Técnico y Económico de la Pesca (CCTEP) -institución encargada de asesorar a la Comisión en asuntos de gestión pesquera- alerta del impacto significativo de la pesca recreativa, el Consejo podrá decidir, mediante la celebración de acuerdos con uno o varios Estados u organizaciones internacionales, aplicar a la pesca recreativa medidas específicas de gestión (autorizaciones de pesca y las declaraciones de capturas).

A su vez, en aras de combatir la pesca INDNR, la normativa de control exige que ningún buque pesquero pueda abandonar el puerto sin una licencia de pesca. La licencia, instrumento jurídico de control administrativo previo sobre la pesca por antonomasia, resulta también de aplicación a la pesca de recreo, especialmente en el caso de las capturas de poblaciones de peces sensibles, como la anguila, el bacalao o el atún rojo.

Teniendo en cuenta que el Reglamento 1224/2009 de control fue elaborado con anterioridad a la actual PPC urge una revisión profunda ante la conveniencia de simplificar el marco legislativo, reducir la carga administrativa innecesaria, mejorar la disponibilidad, la fiabilidad y la integridad de los datos y la información sobre la pesca -sobre todo de los datos sobre capturas-, y eliminar aquellos obstáculos que dificulten el desarrollo de una cultura de cumplimiento y trato equitativo de los pescadores dentro de un Estado miembro y entre distintos Estados miembros. ${ }^{28}$

\footnotetext{
28 Propuesta de Reglamento del Parlamento Europeo y del Consejo por el que se modifica el Reglamento (CE) n. 0 1224/2009 del Consejo, y se modifican los Reglamentos (CE) n. $.768 / 2005$, (CE) n. $.1967 / 2006$ y (CE) n. $.1005 / 2008$ del Consejo y el Reglamento (UE) 2016/1139 del
} 
La propuesta de reforma del Reglamento de control, que presumiblemente verá la luz en el año 2022, incluye aspectos interesantes y de gran calado para el futuro del sector recreativo ${ }^{29}$. Teniendo en cuenta los importantes efectos de la pesca recreativa, el texto de reforma propuesto considera necesario disponer de herramientas específicas que permitan un control uniforme, eficaz y exhaustivo de dicha actividad por parte de todos los Estados miembros, estableciendo un sistema sancionador adecuado en caso de incumplimiento. Por ejemplo, se pretende incorporar la obligación dirigida a los Estados miembros de afianzar el sistema de registro y de concesión de licencias, tanto para las embarcaciones como para los pescadores individuales, con el objetivo de recopilar información fehaciente de las capturas recreativas y los datos de quienes las realizan. ${ }^{30}$

Igualmente, la propuesta de nuevo reglamento mantiene la prohibición de vender las capturas, y amplía, de manera novedosa y oportuna, el ámbito de aplicación del reglamento hacia las actividades pesqueras recreativas organizadas por entidades comerciales del sector turístico y de la competición deportiva ${ }^{31}$. Asimismo, resulta de gran interés la exigencia a los Estados miembros de controlar todos los buques de pesca recreativa que ejerzan su actividad en

Parlamento Europeo y del Consejo en lo que respecta al control de la pesca, COM (2018) 368 final, de 30 de mayo de 2018, p. 1-99.

${ }^{29}$ Fruto de los últimos debates en el seno del PE sobre la reforma del Reglamento de control de la pesca, en marzo de 2021 se presentaron numerosas enmiendas, algunas muy polémicas para el sector pesquero comercial que afectan igualmente al sector recreativo. Es el caso de la obligatoriedad para determinados buques de la instalación de sistemas de seguimiento electrónico para el control de la obligación de desembarque, incluidos sistemas de CCTV de grabación continua (cámaras a bordo), así como los incentivos para el uso de dichos sistemas. $<$ https://europa-azul.es/camaras-a-bordo-de-pesqueros/> ([Última consulta, 31 de mayo de 2021]).

${ }^{30}$ La propuesta de reforma, en su artículo 55 relativo a la pesca recreativa, se exige a los Estados miembros: a) establecer un sistema de registro o concesión de licencias que controle el número de personas físicas y jurídicas que practican la pesca recreativa; $y, b$ ) recopilar datos sobre las capturas procedentes de dicha pesca a través de mecanismos de notificación de capturas u otros mecanismos de recogida de datos basados en una metodología que se notificará a la Comisión. En el caso de las especies sujetas a las medidas de conservación de la Unión aplicables a la pesca recreativa, las declaraciones de capturas deben presentarse a las autoridades competentes y debe establecerse un sistema de registro o de concesión de licencias a las embarcaciones.

${ }^{31}$ Según el párrafo 60 del artículo 55 de la propuesta de reforma del Reglamento de control, la regulación contenida en el mismo se aplicará a las actividades de pesca recreativa, tanto a las llevadas a cabo con el apoyo de un buque, buceando, a pie o mediante el uso de cualquier método de captura o recolección, incluidas las actividades de pesca organizadas por entidades comerciales en el sector turístico y en el sector de la competición deportiva, así como en marco del turismo de pesca y con buques fletados para actividades de pesca recreativa 
"zonas de pesca restringida", es decir, en aquellas zonas marinas en la que las actividades pesqueras están temporal o permanentemente restringidas 0 prohibidas $^{32}$.

Independientemente de las competencias de control de los Estados miembros, la Comisión puede hacer uso de su facultad de ejecución, de conformidad con el procedimiento de examen, ${ }^{33} \mathrm{y}$ adoptar normas de desarrollo en lo relativo al sistema de registro o concesión de licencias, la localización de buques y el control de las artes de pesca para las pesquerías recreativas. Sin embargo, la nueva propuesta de reforma — pendiente de superar determinadas fases de negociación hasta su aprobación - facultaría a la Comisión, en función de la nueva reforma del artículo 55, a adoptar actos delegados, en lugar de actos de ejecución, con objeto de completar el Reglamento mediante normas de desarrollo ${ }^{34}$. Debe recordarse que la Comisión elabora y adopta los actos delegados tras consultar con grupos de expertos, compuestos por representantes de cada país de la UE, que pueden reunirse periódicamente o de manera ocasional. Una vez que la Comisión adopta el acto, el Parlamento y el Consejo disponen generalmente de dos meses para formular objeciones. Si no lo hacen, el acto delegado entra en vigor. Teniendo en cuenta este procedimiento se entiende que, el acceso a la información, la participación efectiva en la elaboración de normas de desarrollo sobre cuestiones atinentes a la PMR, y la capacidad de influencia en la toma de decisiones por parte de los actores con intereses legítimos quedaría ampliamente garantizada si prospera esta propuesta de modificación.

32 Considerando 29 de la Propuesta de Reglamento del Parlamento Europeo y del Consejo Reglamento de control de 2018.

${ }^{33}$ El procedimiento de examen está previsto en el artículo 5 del Reglamento (UE) n.ำ 182/2011 del Parlamento Europeo y del Consejo, de 16 de febrero de 2011, por el que se establecen las normas y los principios generales relativos a las modalidades de control por parte de los Estados miembros del ejercicio de las competencias de ejecución por la Comisión, publicado en el Diario Oficial de la Unión Europea, L 55, de 28 de febrero de 2011, p. 13-18.

${ }^{34}$ En concreto, las normas de desarrollo que se podrán aprobar mediante actos delegados guardarán relación, según la propuesta del PE, con los sistemas de registro o concesión de licencias para la pesca recreativa de especies o poblaciones específicas; la notificación por el capitán de un buque pesquero; la recogida de datos y el registro y presentación de los datos de capturas a través de un formulario o aplicación sencillos, gratuitos y armonizados; la localización de los buques empleados en el turismo de pesca y los buques fletados para actividades de pesca recreativa; y, el control y el marcado de los artes utilizados en la pesca recreativa de modo sencillo y proporcionado. 
Finalmente, en el ámbito del régimen de infracciones y sanciones, la nueva propuesta de reglamento considera infracción grave ejercer actividades de pesca recreativa que infrinjan las normas de la política pesquera común o vender capturas obtenidas a través de la pesca recreativa ${ }^{35}$.

\section{Recopilación y accesibilidad a los datos del sector pesquero recreativo: una tarea pendiente}

De manera reiterada, la comunidad científica viene demandando la necesidad de acceder a datos fiables sobre las pesquerías recreativas con vistas a una gestión pesquera sostenible en aguas europeas. Con este espíritu se aprobó el Reglamento 2017/1004 del Parlamento Europeo y del Consejo, de 17 de mayo de 2017, relativo al establecimiento de un marco para la recopilación, gestión y uso de los datos biológicos, medioambientales, técnicos y socioeconómicos relativos al sector pesquero (en adelante Reglamento de datos) ${ }^{36}$.

Debido a que el objetivo perseguido por el Reglamento de datos difícilmente puede ser alcanzado por los Estados miembros en exclusiva, la UE -en virtud del principio de atribución y de acuerdo con las reglas de subsidiariedad y proporcionalidad del artículo 5 del Tratado de la Unión Europea-, permite a la Comisión adoptar un programa plurianual con vistas a la recopilación y gestión de datos biológicos de todas las poblaciones capturadas o capturadas accesoriamente por actividades de pesca comercial y, en su caso, de pesca recreativa en aguas de la Unión y fuera de ellas, incluyendo la pesca de anguila y de salmón en las aguas interiores correspondientes, así como otras especies diadromas de interés comercial, con el fin de hacer posible un enfoque ecosistémico de la gestión y conservación de la pesca necesarias para el funcionamiento de la política pesquera común ${ }^{37}$. De esta manera, los Estados miembros y aquellos terceros países que tengan soberanía o jurisdicción sobre

\footnotetext{
${ }^{35}$ Artículo 90. h) de la Propuesta de Reglamento de control de 2018.

${ }^{36}$ Reglamento (UE) 2017/1004 del Parlamento Europeo y del Consejo de 17 de mayo de 2017, relativo al establecimiento de un marco de la Unión para la recopilación, gestión y uso de los datos del sector pesquero y el apoyo al asesoramiento científico en relación con la política pesquera común y por el que se deroga el Reglamento (CE) n.ำ199/2008 del Consejo, publicado en el Diario Oficial de la Unión Europea, L 157, de 20 de junio de 2017, p.1-21.

${ }^{37}$ Artículo 5 del Reglamento (UE) 2017/1004 de datos.
} 
las aguas de la misma región marítima coordinarán sus esfuerzos en la recopilación de datos ${ }^{38}$.

Con toda seguridad, la recopilación de datos representa el mayor reto de la PPC de cara a los próximos años. Su finalidad es identificar de manera fiable el número de pescadores recreativos que operan en aguas comunitarias sobre la base de los planes nacionales. En la preparación del plan de trabajo nacional, cada Estado miembro procurará que las partes interesadas pertinentes participen en el nivel apropiado ${ }^{39}$. A fin de obtener la mejor muestra posible de datos sobre PMR, la labor de apoyo del Consejo Internacional para la Exploración del Mar (CIEM) es innegable. ${ }^{40}$ En el año 2010, se creó un grupo de trabajo para discutir y desarrollar un método común para el estudio de la pesca recreativa, con el objeto de proporcionar una descripción exhaustiva de las pesquerías marinas de recreo en cada país del $\mathrm{CIEM}^{41}$.

El problema, hasta la fecha, es que las evaluaciones científicas de las poblaciones de peces marinos europeas han estado centradas en los aspectos socioeconómicos y en la cuantificación de la mortalidad asociada a las extracciones de la pesca comercial, haciendo caso omiso a los efectos de las capturas de la pesca recreativa. Para superar la carencia de una correcta evaluación sobre la PMR, tanto la UE como el CIEM tienen que proporcionar mucho más apoyo y financiación suficiente a la investigación científica en la materia.

Otra cuestión prioritaria, contemplada en la propuesta de reglamento de control, se refiere a la perentoriedad de incluir las actividades relativas a la pesca recreativa en los programas nacionales ${ }^{42}$. Esta obligación de evaluación nacional plantea un desafío para las comunidades autónomas y para España en su

\footnotetext{
${ }^{38}$ lbíd., Artículo 9.

39 Ibíd., Artículo 6.4.

${ }^{40}$ EI CIEM es una organización intergubernamental de base científica, dedicada al estudio de los ecosistemas marinos que proporciona información a la sociedad y asesora a los responsables de la toma de decisiones, en relación con los mares y océanos del mundo, sobre los impactos de las actividades humanas.

${ }^{41}$ ICES. Report of the Planning Group on Recreational Fisheries (PGRFS), Bergen, Norway. ICES CM 2010/ACOM:34. 2010, p.2.

${ }^{42}$ Artículo 46, Reglamento (CE) del Consejo n.ำ 1224/2009, de control.
} 
conjunto, pues se necesita un régimen intervención y control homogéneo, inexistente hasta el momento. A efectos de la recopilación de datos, la armonización autonómica del régimen de licencias facilitaría la obtención de muestras verdaderamente representativas sobre el número los pescadores recreativos en el mar.

\section{Las posibilidades de capturas recreativas en aguas de la Unión}

Fruto de las negociaciones llevadas a cabo en el seno del Consejo de Agricultura y Pesca de la Unión, los ministros del ramo acuerdan cada año las posibilidades de pesca para determinadas poblaciones y grupos de poblaciones de peces en aguas de la Unión, así como en determinadas aguas no pertenecientes a la Unión. Con este objeto se aprueba el Reglamento (UE) 2021/92 del Consejo, de 28 de enero de 2021, por el que se establecen para 2021 las posibilidades de pesca, el cual amplía su ámbito de aplicación a la $\mathrm{PMR}^{43}$. Además, según su artículo 26 señala que: "Si procede, los Estados miembros asignarán un cupo específico para la pesca recreativa a partir de las cuotas que les hayan sido asignadas conforme a lo dispuesto en el anexo ID".

Según el Reglamento (UE) 2021/92 citado, las medidas sobre las posibilidades de pesca recreativa, sin perjuicio de las medidas nacionales más restrictivas, son consecuencia de la delicada situación de determinadas poblaciones de peces como la lubina, la anguila, el pez espada o el atún rojo, todas ellas especies objetivo de las pesquerías recreativas. A su vez, defiende que, dentro de los límites fijados por los dictámenes científicos, se siga empleando la práctica de captura y liberación inmediata y el límite de capturas y en su caso, se establezcan periodos de veda.

Teniendo en cuenta las circunstancias medioambientales, sociales y económicas, y, especialmente, la dependencia que respecto de esas

\footnotetext{
${ }^{43}$ Artículo 2: "El presente Reglamento se aplica también: a) la pesca recreativa, cuando dicha pesca se mencione expresamente en las disposiciones pertinentes del presente Reglamento (...)". Reglamento (UE) 2021/92 del Consejo de 28 de enero de 2021, por el que se establecen para 2021 las posibilidades de pesca para determinadas poblaciones y grupos de poblaciones de peces, aplicables en aguas de la Unión y, en el caso de los buques pesqueros de la Unión, en determinadas aguas no pertenecientes a la Unión, publicado en el Diario Oficial de la Unión Europea, L 31, de 29 de enero de 2021, p. 31-192.
} 
poblaciones tienen los pescadores profesionales en las comunidades costeras, estas medidas ofrecen un equilibrio adecuado entre los intereses de los pescadores profesionales y los de quienes practican la pesca recreativa.

En concreto, el atún rojo ha sido durante años objeto de un especial tratamiento por medio de un plan de recuperación, actualmente regulado por el Reglamento 2016/1627 de 14 de septiembre de 2016, encargado de regular el plan de recuperación plurianual para el atún rojo del Atlántico oriental y el Mediterráneo ${ }^{44}$. En 2019, se puso en marcha una propuesta de modificación del anterior Reglamento, entre cuyas novedades incorpora la exigencia a los Estados miembros de trasladar a la Comisión la lista de los buques de recreo a los que se haya concedido una autorización de pesca, acompañada de información específica sobre nombre del buque, número de registro, número de registro CICAA (si lo tiene), etc. ${ }^{45}$

Los planes plurianuales o a largo plazo surgen con la reforma de la PPC de 2002, para aquellas poblaciones de peces que se habían visto diezmadas hasta unos niveles peligrosamente bajos (planes de recuperación), aunque en la actualidad, su aplicación se está normalizando como método de gestión de las principales poblaciones de peces comerciales de la UE. Los planes plurianuales no se limitan a proporcionar los totales admisibles de capturas (TAC), sino que incluyen medidas como las zonas de veda, medidas técnicas sobre las artes de pesca, procedimientos de seguimiento, inspección y control, así como precisiones para la gestión del esfuerzo pesquero (límites de los días pasados en el mar). ${ }^{46}$

Según el artículo 18 del Reglamento 2016/1627, cada Estado miembro que disponga de cuota de atún rojo regulará las pesquerías deportivas y de recreo

\footnotetext{
44 Reglamento (UE) 2016/1627 del Parlamento Europeo y del Consejo de 14 de septiembre de 2016, relativo a un plan de recuperación plurianual para el atún rojo del Atlántico oriental y el Mediterráneo y por el que se deroga el Reglamento (CE) n.․ 302/2009 del Consejo, publicado en el Diario Oficial de la Unión Europea, L 252, de 16 de septiembre de 2016, p. 1- 52.

${ }^{45}$ Artículo 23, relativo a las condiciones específicas para la pesca de recreo, contenido en la Propuesta de Reglamento del Parlamento Europeo y del Consejo por el que se establece un plan de ordenación plurianual para el atún rojo del Atlántico oriental y el Mediterráneo, y se modifican los Reglamentos (CE) n.o 1936/2001, (UE) 2017/2107 y (UE) 2019/833 y se deroga el Reglamento (UE) 2016/1627, COM (2019) 619 final 2019/0272 (COD), de 28 de noviembre de 2019, p.1-48.

${ }^{46}$ Según su artículo 11 del Reglamento 2016/1627, se permitirá la pesca deportiva y de recreo de atún rojo del Atlántico oriental y el Mediterráneo del 16 de junio al 14 de octubre.
} 
asignándoles una cuota específica, previa autorización, e informará al respecto a la Comisión en el momento de la transmisión de su plan de pesca, pues las capturas de atún rojo muerto se deducirán de la cuota correspondiente al Estado. A su vez, la Comisión transmitirá esta información sin demora a la Secretaría de la CICAA.

En el plano nacional, el Real Decreto 46/2019, de 8 de febrero, por el que se regula la pesquería de atún rojo en el Atlántico Oriental y Mediterráneo ${ }^{47}$, establece en su artículo 4 la distribución de cuota asignada al Reino de España y, de manera reciente, la Resolución de 12 de mayo de 2020, de la Secretaría General de Pesca del Ministerio de Agricultura, Pesca y Alimentación ha aprobado las disposiciones de aplicación del plan de recuperación del atún rojo para el $2020^{48}$.

Por otra parte, cuando proceda, y dentro del paraguas del régimen de control deben aplicarse medidas técnicas a la pesca recreativa. De esta forma, el Reglamento 2019/1241 del Parlamento Europeo y del Consejo de 20 de junio de 2019, sobre la conservación de los recursos pesqueros y la protección de los ecosistemas marinos con medidas técnicas, resulta de aplicación a la pesca recreativa ${ }^{49}$. En los casos en los que dicha pesca tenga un impacto significativo en una región determinada, la Comisión estará facultada para adoptar actos delegados a fin de modificar el presente Reglamento en aplicación de la pesca recreativa ${ }^{50}$.

\footnotetext{
${ }^{47}$ Real Decreto 46/2019, de 8 de febrero, publicado en el BOE n. 35 , de 9 de febrero de 2019.

${ }^{48}$ La Resolución de 12 de mayo de 2020, de la Secretaría General de Pesca del Ministerio de Agricultura, Pesca y Alimentación de España, publicada en el BOE n.․ 148, de 25 de mayo de 2020, establece que la cuota de atún rojo concedida a España para 2020 ascendía a 6.107,60 toneladas.

${ }^{49}$ Reglamento (UE) 2019/1241del Parlamento europeo y del Consejo de 20 de junio de 2019, sobre la conservación de los recursos pesqueros y la protección de los ecosistemas marinos con medidas técnicas, y por el que se modifican los Reglamentos (CE) $n . .02019 / 2006$ y (CE) $n .$. 1224/2009 del Consejo y los Reglamentos (UE) n. 1380/2013, (UE) 2016/1139, (UE) 2018/973, (UE) 2019/472 y (UE) 2019/1022 del Parlamento Europeo y del Consejo, y por el que se derogan los Reglamentos (CE) n.ㅇ 894/97, (CE) n.. 850/98, (CE) n.ㅇ 2549/2000, (CE) n.. 254/2002, (CE) n. $.812 / 2004$ y (CE) n. $.92187 / 2005$ del Consejo, publicado en el Diario Oficial de la Unión Europea, L 198, de 25 de julio de 2019, p. 105-201.

${ }^{50}$ Según el artículo 7.1.g) del Reglamento 2019/1241 sobre medidas técnicas, "queda prohibido capturar o recoger especies marinas utilizando cualquier tipo de proyectil, con la excepción de los utilizados para el sacrificio de atunes enjaulados o capturados en almadraba y de arpones y fusiles de pesca submarina utilizados en la pesca recreativa sin escafandra autónoma, desde el alba hasta el ocaso".
} 


\section{Vertiente financiera de la política pesquera común}

Prácticamente desde su inicio, la PPC contó con el apoyo financiero de los fondos estructurales, hasta que en 1995 se creó el Instrumento Financiero de Orientación de la Pesca (IFOP). Años más tarde, ante la necesidad de garantizar una plena coherencia con el Reglamento base de la PPC de 2002, se planteó un nuevo instrumento financiero denominado Fondo Europeo de Pesca (FEP) que entró en vigor el 1 de enero de 2007 con un horizonte de vigencia de siete años ${ }^{51}$. Gracias a este último, los Estados miembros serían los encargados de decidir la asignación de los fondos sobre la base de un plan estratégico nacional diseñado en colaboración con la Comisión, que queda plasmado en su ejecución en los programas nacionales operativos.

Actualmente, el Fondo Europeo Marítimo y de la Pesca (FEMP) encuentra su base jurídica en el Reglamento (UE) № 508/2014 del PE y del Consejo, de 15 de mayo de 2014, para el período 2014-202052. Entre las prioridades del FEMP destacan la ayuda a los pescadores en su transición a la pesca sostenible, el apoyo a las comunidades costeras europeas para la diversificación de sus economías, la financiación de proyectos orientados a la generación de nuevos empleos y la mejora de la calidad de vida.

En concreto, y con especial referencia a la PMR, el artículo 77.2 del FEMP, considera subvencionable la recopilación, la gestión y el uso de datos en lo relativo a "(...) la observación en el mar de la pesca comercial y recreativa, incluida la observación de las capturas accesorias de organismos marinos tales como mamíferos y aves marinos."

A punto de finalizar su periodo de vigencia, la Comisión ha avanzado algunas cuestiones sobre la futura financiación europea en materia de pesca para el

\footnotetext{
${ }^{51}$ El importe del FEP, ligeramente por encima de 4.300 millones de euros para el periodo 20072013 , tenía como destino, en un $75 \%$, las regiones menos desarrolladas de la UE, y operaba mediante la participación del Fondo en la financiación de proyectos presentados por empresas, poderes públicos u organismos representativos.

${ }^{52}$ Reglamento (UE) n.․ 508/2014 del Parlamento Europeo y del Consejo, de 15 de mayo de 2014, relativo al Fondo Europeo Marítimo y de Pesca, y por el que se derogan los Reglamentos (CE) n.. 2328/2003, (CE) n.o 861/2006, (CE) n. $.1198 / 2006$ y (CE) n. $.9791 / 2007$ del Consejo, y el Reglamento (UE) n. ${ }^{-1255 / 2011}$ del Parlamento Europeo y del Consejo, publicado en el Diario Oficial de la Unión Europea, de 20 de mayo de 2014, L 149, p. 1- 66.
} 
período 2021-2027.53 Entre sus directrices principales, el FEMP seguirá apoyando prácticas de pesca más sostenibles, con especial hincapié en los pescadores a pequeña escala que representa la mitad del empleo del sector en Europa. Las comunidades costeras recibirán un mayor apoyo para la diversificación de actividades dentro del propio sector, la creación de asociaciones locales y la transferencia de tecnología en todos los sectores de la economía azul -incluidos la acuicultura y el turismo costero-, lo cual beneficia a la pesca de recreo.

En el marco del futuro FEMP se señala que, ante las medidas de ajuste de las flotas pesqueras mediante el desguace o retirada de buques, la readaptación a otras actividades puede dar lugar a una mayor presión de la pesca recreativa en el ecosistema marino. En este caso, únicamente debe concederse apoyo a este sector si se ajusta a la PPC y a los objetivos de los planes plurianuales pertinentes.

\section{ELEMENTOS VERTEBRADORES PARA LA INTEGRACIÓN EFECTIVA DE LA PESCA MARÍTIMA DE RECREO EN LA POLÍTICA PESQUERA DE LA} UE

La consolidación de la PPC que conocemos actualmente surge gracias a la sustancial reforma llevada a cabo por el Reglamento 2371/2002 del Consejo, sobre la conservación y la explotación sostenible de los recursos pesqueros en virtud de la PPC ${ }^{54}$. Aunque su aplicación consiguió grandes avances -reducir la capacidad de la flota, aplicar los planes plurianuales o el fomento de la participación de todas las partes interesadas por medio de los Consejos Consultivos Regionales (CCR) - sus logros quedaron muy lejos de su principal

\footnotetext{
${ }^{53}$ Propuesta de Reglamento del Parlamento Europeo y del Consejo relativo al Fondo Europeo Marítimo y de Pesca y por el que se deroga el Reglamento (UE) $n$. o 508/2014 del Parlamento Europeo y del Consejo. COM (2018) 390 final 2018/0210 (COD). Estrasburgo, 12 de junio de 2018, p. 1-66. El FEMP cofinanciará proyectos junto con los flujos nacionales de financiación y cada Estado miembro recibirá un porcentaje del presupuesto total. Los Estados miembros elaboran sus programas operativos nacionales y una vez aprobados por la Comisión las autoridades nacionales deciden qué proyectos desean apoyar.

54 Reglamento (CE) n.o 2371/2002 del Consejo, de 20 de diciembre de 2002, sobre la conservación y la explotación sostenible de los recursos pesqueros en virtud de la política pesquera común, publicado en el Diario Oficial de la Unión Europea, L 358, de 31 de diciembre de 2002, p. 59-80.
} 
objetivo: lograr establecer una pesca sostenible en el ámbito de los ecosistemas marinos de todas las aguas europeas.

En el año 2009, la Comisión Europea, a través del Libro Verde de reforma de la PPC, ya detectó deficiencias estructurales en torno a la diversificación de las actividades pesqueras y manifestó su compromiso en corregirlas ${ }^{55}$. La respuesta por parte de los sectores afectados, en concreto la de la European Anglers Alliance (EEA), ha sido constante en su defensa de la pesca recreativa como grupo de interés con derecho propio en el marco de la PPC. ${ }^{56}$

Adoptando los principios de la nueva gobernanza europea (Artículo 3 del Reglamento (UE) N. 1380/2013, sobre la PPC), cabría plantearse si determinadas cuestiones relativas a la PMR podrían quedar integradas en el ámbito competencial exclusivo de la UE con vistas a la aprobación de una regulación común a través de la PPC. ${ }^{57}$ Durante la elaboración de la actual política pesquera de la UE, algunas voces plantearon no solamente que la pesca recreativa fuera considerada un grupo de interés con derecho propio en la ordenación pesquera europea, sino que, a la vista de su significativo valor socioeconómico, se debería iniciar el diseño de cuantas medidas técnicas específicas fueran necesarias para alcanzar su plena integración en el marco común de la pesca. ${ }^{58}$

En fechas relativamente recientes, el Parlamento Europeo, consciente de la

\footnotetext{
55 "La pesca, con su amplia proporción de pequeñas y medianas empresas, desempeña una importante función en el tejido social y la identidad cultural de un gran número de regiones costeras europeas. La renta de muchas de estas comunidades, algunas de las cuales presentan escasas posibilidades de diversificación económica, sigue dependiendo de la pesca. Por consiguiente, es fundamental garantizar un futuro para los pescadores que practican la pesca costera, artesanal y recreativa, teniendo plenamente en cuenta la especial situación de las pequeñas y medianas empresas". Vid., Comisión Europea, Libro Verde de reforma de la Política Pesquera Común, 2009, p. 15.

56 Desde hace décadas, el sector recreativo europeo representado a través de la European Anglers Alliance (EEA) ha estado reclamando superar la visión tradicional de la gestión pesquera europea que venía reconociendo al sector comercial como el único grupo interesado en los recursos pesqueros. <https://www.eaa-europe.org/> [Última consulta, 31 de mayo de 2021].

${ }^{57}$ En relación a la materia pesquera, la conservación de los recursos biológicos marinos en aguas bajo la soberanía o jurisdicción de los Estados miembros es competencia exclusiva de la UE dentro del marco de la PPC (art. 3.1.d TFUE), lo que se traduce en la potestad de legislar y adoptar actos jurídicamente vinculantes en la materia; mientras que los Estados, en cuanto tales, únicamente podrán hacerlo si son facultados por la Unión para legislar o para aplicar actos de la Unión (art. 2.1 TFUE).

${ }^{58}$ Comisión Europea, Resumen de la consulta sobre la reforma de la Política Pesquera Común, Documento de trabajo de los servicios de la Comisión. SEC (2010) 428 final, 2010, p. 18.
} 
importante repercusión económica, social y medioambiental de la pesca recreativa en las regiones marítimas europeas manifestó, a través de Resolución de 12 de junio de 2018 sobre la situación de la pesca recreativa en la Unión, la necesidad de tener en cuenta a la PMR en el marco de la PPC y en el ámbito de aplicación de cualquier normativa futura en la materia. ${ }^{59}$ En concreto, señaló la importancia de contar con un programa común y estable de recopilación de datos económicos que permita reconocer a las pesquerías recreativas como un sector diferenciado de la PPC junto a la pesca comercial y la acuicultura. A la vez, alertó de la necesidad de establecer normas básicas para la gestión de la pesca recreativa, proponiendo elaborar un catálogo de las actividades de la pesca recreativa que incluyera información sobre las artes y operaciones de pesca, una descripción de las zonas de pesca, las especies objetivo y las capturas accidentales.

Tras este informe del PE queda patente la necesidad de incluir la pesca recreativa en la nueva PPC, ya sea en el seno de los futuros planes de gestión -siempre que incorporen datos completos y fidedignos fruto de una exhaustiva evaluación previa, como sucede con la pesca comercial- ; o bien, mediante la aprobación de una serie de Directivas que, con un ámbito de aplicación regional por cuencas marinas, permitan a los Estados miembros diseñar y aplicar herramientas de gestión orientadas a alcanzar objetivos comunes en cuanto a la PMR. De esta forma y ante los limitados avances normativos llevados a cabo, una regulación común sobre los aspectos señalados por el PE, tal vez facilitaría la ordenación de las actividades pesqueras en orden a superar los conflictos entre los diversos sectores, al tiempo que optimizaría el potencial de las actividades recreativas en beneficio del desarrollo socioeconómico de las comunidades costeras. En este sentido, la toma en consideración de las particularidades de cada zona marina mediante un enfoque regionalizado se atisba como el primer paso en la dirección señalada.

\section{Importancia de la adecuada ordenación de usos en el espacio marítimo}

59 Parlamento Europeo, Resolución de 12 de junio de 2018, sobre la situación de la pesca recreativa en la Unión, (2017/2120 (INI)), p.8. 
El conflicto por el acceso a los recursos pesqueros es una característica común de la gestión marina y costera que habitualmente implica a la pesca profesional, a la pesca recreativa y al turismo en general. ${ }^{60}$ Normalmente, las controversias se acentúan ante la escasez del recurso y en función de las características sociales y económicas de las partes involucradas.

Por regla general, la pesca profesional suele estar regulada estrictamente, mientras que la pesca recreativa goza de un privilegiado derecho de pesca, solamente condicionado al otorgamiento de la preceptiva licencia o permiso. Esta realidad, unida a la generalizada creencia del impacto ambiental relativamente bajo que produce el pescador recreativo a nivel individual -en concreto los que utilizan métodos respetuosos con el medio ambiente como la captura y liberación- favorece que la PMR se sitúe, en ocasiones, como una actividad favorecida frente a cualquier otro uso.

Con objeto de gestionar adecuadamente el acceso a los recursos pesqueros por parte de los distintos sectores de la pesca, la ordenación espacial marina y la creación de zonas marinas protegidas se posicionan como medidas prioritarias. De hecho, la vocación de la ordenación del espacio marítimo (OEM) — también conocida como Marine Spatial Planning (MSP)_ está cobrando una gran fuerza en todo el mundo por la importancia estratégica de las zonas costeras y litorales y la necesidad de regular los usos que interfieren en un mismo espacio. ${ }^{61}$

\footnotetext{
60 Michelle Voyer, Kate Barclay, Alistair Mcilgorm, Nicole Mazur, "Connections or conflict? A social and economic analysis of the interconnections between the professional fishing industry, recreational fishing and marine tourism in coastal communities in NSW, Australia", Marine Policy, 76: 2017, 114-121, p. 2.

61 Francisco J. Sanz Larruga, "La nueva ordenación del espacio marítimo: análisis del Real Decreto 363/2017, de 8 de abril”, Práctica Urbanística oㅡ 150, enero-febrero 2018, Editorial Wolters Kluwer, p. 1. En la doctrina española, también son de gran interés en otros los trabajos: José Luis Suárez de Vivero y Juan Carlos Rodríguez Mateos, "The Spanish approach to marine spatial planning. Marine Strategy Framework Directive vs. EU Integrated Maritime Policy", Marine Policy, 36, 2012, p. 18-27; Estanislao Arana García, Asensio Navarro Ortega, y Francisco Javier Sanz Larruga (Dirs.): La ordenación jurídica del medio marino en España: estudios sobre la Ley 41/2010, de protección del medio marino, Civitas-Thomson-Reuters, Cizur Menor, 2012, p. 601646; Blanca Lozano Cutanda, "Real Decreto 363/2017, de 8 de abril, la ordenación de los distintos usos y de las actividades económicas en el espacio marítimo", Diario La Ley, Número 8999, 2017; y Ángel Menéndez Rexach, "La ordenación del espacio marítimo", en María del Carmen Núñez Lozano (Dir.), Estudios Jurídicos sobre el litoral, Tirant lo Blanch, Valencia, 2016, p. 23-53.
} 
La ordenación del espacio marino ha adquirido carta de naturaleza comunitaria con la aprobación de la Directiva 2014/89/UE ${ }^{62}$. En cuanto a la integración de la PMR en los planes de ordenación del espacio marítimo, son los Estados miembros quienes deben procurarán contribuir al desarrollo sostenible de las distintas actividades con incidencia en el mar, incluyendo a la pesca ${ }^{63}$.

En relación con las áreas marinas protegidas, la Directiva 2008/56/CE (Directiva marco sobre la estrategia marina $)^{64}$ es la encargada de establecer el marco para que los Estados miembros adopten las decisiones necesarias para el logro 0 mantenimiento de un buen estado medioambiental del medio marino, entre las que se encuentran medidas de protección espacial como la creación de zonas especiales de conservación, zonas de protección especial o zonas marinas protegidas. En este sentido, la PPC debe tener en cuenta el impacto medioambiental de la pesca y adaptarse a los objetivos que persigue la Directiva sobre la estrategia marina, incluidas las regulaciones en materia de AMPs.

En ocasiones, la interpretación de las reglas de asignación sobre los recursos pesqueros sobre la base del valor económico que cada sector aporta a la sociedad puede dar lugar a controversias. Desde el ámbito de la pesca recreativa y del sector turístico se argumenta que los beneficios que proporcionan las actividades asociadas son mayores que los que pueda generar cualquier otra

62 Directiva 2014/89/UE por la que se establece un marco para la ordenación del espacio marítimo", publicada en el Diario Oficial de la Unión Europea, L 257, de 28 de agosto de 2014, p. $135-145$.

${ }^{63}$ La Directiva 2014/89/UE se transpuso a España mediante el Real Decreto 363/2017, de 8 abril, cuyo artículo 10, relativo al contenido de los planes de ordenación del espacio marítimo - encargados de la distribución espacial y temporal de las actividades y usos, existentes y futuros, de las aguas marinas españolas - tendrán en cuenta las interacciones entre las actividades y usos e intereses posibles, entre los que incluye las zonas de pesca y las actividades turísticas, recreativas, culturales y deportivas, entre otras.

64 Directiva 2008/56/CE por la que se establece un marco de acción comunitaria para la política del medio marino, publicada en el Diario Oficial de la Unión Europea, L 164, de 25 de junio de 2008, págs. 19-40. Sobre esta materia son destacables los trabajos de Mercedes Ortiz García, Las áreas marinas protegidas: mayor importancia por el cambio climático, Observatorio de Políticas Ambientales 2020, en Gerardo García-Álvarez García, Jesús Jordano Fraga, Blanca Lozano Cutanda, Alba Nogueira López (Coord.), 2020, p. 631-648; Blanca Soro Mateo, Hacia una gobernanza de las áreas marinas protegidas: estado de la cuestión y algunos retos a vencer, Administración de Andalucía: revista andaluza de administración pública, oo. 104, 2019, p. 135174; y María Giménez Casalduero, "Las áreas marinas protegidas: nuevas perspectivas a la luz de la Ley 42/2007, del patrimonio natural y de la biodiversidad", Revista Catalana de Dret Ambiental, Vol. 1, n. ${ }^{\circ}$ 1, 2010, p. 1-31. 
actividad y por lo tanto se les debe dar prioridad. Sin embargo, en ocasiones las valoraciones coste/beneficio se realizan de forma aislada al resto de variables socioeconómicas como el empleo del sector pesquero profesional ${ }^{65}$.

Por tanto, de cara a una propuesta de regulación sobre la ordenación de los usos pesqueros que exige la Directiva OEM habría que evaluar de manera integral todos los factores ambientales, sociales y económicos de las comunidades costeras implicadas. Del mismo modo que el turismo (incluido el turismo de pesca recreativa) y la pesca profesional no suelen excluirse mutuamente, las disputas entre pescadores profesionales y recreativos debe armonizarse por medio de reglas jurídicas apropiadas de ordenación de usos, máxime cuando la exclusión de un grupo no significa un beneficio automático para el resto. ${ }^{66} \mathrm{La}$ aplicación de mecanismos de solución de controversias basados exclusivamente en el grado de impacto ambiental que provocan y en el valor económico de los sectores competidores puede resultar fallido y dar lugar a decisiones y propuestas jurídicas de ordenación equivocadas, pues estos criterios no siempre reconocerán el verdadero alcance o la naturaleza del conflicto.

\section{Aplicación del enfoque regional de gestión pesquera a la pesca marítima de recreo}

La dificultad de adaptar la PPC a las especificidades de la pesca recreativa europea ha propiciado la proliferación de regulaciones estatales y autonómicas con distintos niveles de responsabilidad. Esta situación, no solo genera inseguridad jurídica -pues da lugar a un ordenamiento jurídico disperso y farragoso- sino que facilita, por ejemplo, el que determinados agentes rehúyan las obligaciones normativas de un área determinada practicando la pesca en zonas marinas con una legislación menos robusta ${ }^{67}$.

\footnotetext{
65 Joshua K. Abbott, "Fighting over a Red Herring: The Role of Economics in RecreationalCommercial Allocation Disputes", Marine resource economics, 2015, 30, 1-20

${ }^{66}$ Michelle Voyer, Kate Barclay, Alistair Mcilgorm, Nicole Mazur, "Connections or conflict? ..., cit., pág.10.

${ }^{67}$ Consejo Económico y Social, Informe CES 01/2013, La reforma de la Política Pesquera Común, Madrid, 2013, p. 52.
} 
El principio de regionalización se introduce en el marco de la nueva gobernanza de la PPC, en virtud del artículo 3.b) del Reglamento 1380/2013. Gracias a este sistema de cooperación regional se abre un nuevo escenario en la arquitectura jurídica europea que no pasa desapercibido para el sector pesquero recreativo.

Aunque este modelo permite a los Estados miembros cooperar en la aplicación de medidas de conservación, en caso de que no lleguen a un acuerdo o no se alcancen los objetivos perseguidos, la nueva gobernanza de la pesca europea admite la intervención de la Comisión por medio de actos delegados o de ejecución en relación con una zona geográfica determinada ${ }^{68}$. De esta manera, aplicando el procedimiento de delegación al ámbito recreativo de la pesca, aquellos Estados miembros que ostenten un interés directo podrían acordar recomendaciones conjuntas en cuanto a las medidas de conservación o planes plurianuales pertinentes, y en caso que no logren acordar estas recomendaciones, o si las acordadas no se consideran compatibles con los objetivos y las metas de que se trate, la Comisión podría presentar una propuesta de medidas de conformidad con el Tratado. Por ende, los principios de la nueva gobernanza pesquera europea contribuyen a superar el secular centralismo en la toma de decisiones, convirtiendo el cumplimiento normativo regional en un aliciente para los Estados miembros y las demás partes interesadas.

Asimismo, la aplicación del principio de regionalización resulta compatible con los fines perseguidos por la Política Marítima Integrada (PMI) y la Política de protección del medio marino de la $\mathrm{UE}^{69}$. Como se ha señalado anteriormente, ambos instrumentos comunitarios persiguen adoptar medidas de conservación de carácter regional mediante un modelo de gestión inclusivo en cuanto los usos pesqueros (incluidos los recreativos). Por un lado, la Directiva Marco sobre la Estrategia Marina, 2008/56/CE de 17 de junio, establece la obligación para los Estados miembros de elaborar una estrategia para cada región o subregión marina (o subdivisión menor que cada estado pueda determinar), con el objeto de lograr o mantener un buen estado medioambiental del medio marino a más

\footnotetext{
${ }^{68}$ Artículo 46 del Reglamento 1380/2013 de la PPC.

${ }^{69}$ Comunicación de la Comisión al Parlamento Europeo, al Consejo, al Comité Económico y Social Europeo y al Comité de las Regiones Sobre una política marítima integrada para la Unión Europea, COM (2007) 574, Bruselas, 10 de octubre de 2007, p. 1-16.
} 
tardar en el año 2020; por otro, la Comisión ha presentado, en el marco de la PMI, las estrategias de cuencas marítimas para todos los mares y océanos de la Unión ${ }^{70}$.

Ciertamente, la ubicación de la pesca marítima de recreo encuentra acomodo en la Política Marítima Integrada (PMI) de la Unión Europea pues, siguiendo sus postulados sobre la interconexión de todas las actividades marítimas de cara a su ordenación, el enfoque holístico que propugna le resulta directamente de aplicación.

El espíritu de la PMI se fundamenta en la necesidad de respaldar el desarrollo sostenible de los mares y océanos, mediante un procedimiento de adopción de decisiones coordinado, coherente y transparente en relación con las políticas sectoriales de la Unión que afectan al medio marino, incluso a través de estrategias regionales basadas en la cuenca marítima con el objetivo de alcanzar el buen estado medioambiental, tal y como se establece en la Directiva 2008/56/CE (Directiva sobre la estrategia marina). Con la misma vocación de complementar la PMI de la UE se aprueba la Directiva 2014/89/UE por la que se establece un marco para la ordenación del espacio marítimo (Directiva OEM) cuya finalidad, manifiestamente más amplia que la perseguida en la Directiva 2008/56/CE, pretende: "fomentar el crecimiento sostenible de las economías marítimas, el desarrollo sostenible de los espacios marítimos y el aprovechamiento sostenible de los recursos marinos".

De este modo, la PMI se configura como una política global que agrupa un conjunto de ámbitos relacionados con el medio marino -como los transportes marítimos, la energía, la vigilancia y el control de los mares, el turismo, el medio ambiente, la investigación, y por supuesto la pesca-con el objetivo de promover la adecuada distribución del espacio marítimo entre los usos pertinentes, mediante un marco de ordenación que para la correcta ejecución de los planes elaborados por los Estados miembros.

\footnotetext{
70 Una estrategia de cuenca marítima es un instrumento basado en un enfoque regional de gestión que cuenta con la cooperación de países que comparten una misma cuenca marítima, con el fin de abordar desafíos y oportunidades comunes para el desarrollo de la economía marítima y la protección del medio marino.
} 
En este contexto, tanto la pesca comercial como la recreativa ocupan un papel fundamental, máxime cuando el instrumento estratégico transversal que supone la ordenación del espacio marítimo europeo persigue, precisamente, evitar los conflictos derivados del solapamiento de aquellas actividades que coexisten en un mismo espacio marino. Sin embargo, por una parte, no puede obviarse que las capturas de la pesca recreativa pueden llegar a tener un impacto significativo, tal y como afirman los estudios científicos en la materia y la propia PPC, por lo que resulta aconsejable que sea en el seno de la PPC donde se extremen las precauciones de manera anticipada con la finalidad de equilibrar las poblaciones de peces y la actividad pesquera, y ello en aplicación del artículo 2 del Reglamento (UE) n.- 1380/2013. Por otra parte, alcanzar este objetivo se torna extremadamente complicado si faltan los datos sobre capturas recreativas o si se ignora la importancia económica de las actividades relacionadas con la pesca de recreo.

Partiendo de la base que el nuevo marco de gobernanza de los asuntos marítimos requiere instrumentos intersectoriales que ayuden a los legisladores y a los agentes económicos y ambientales a asociar sus políticas, a interconectar sus actividades y a optimizar el uso del espacio marino y costero de forma medioambientalmente sostenible, resulta imprescindible la mejora de los datos y la información disponible, así como la implementación de instrumentos de ordenación de usos que faciliten su coexistencia.

El desarrollo de las actividades de pesca recreativa no puede realizarse al margen de la gestión normal de los recursos pesqueros, especialmente en el caso de la pesca a pequeña escala y artesanal. Por ello, paralelamente a la aplicación de otros instrumentos globales, la PPC debe orientar el reparto de los recursos entre las actividades profesionales y las recreativas, sobre la base de principios comunes y de los mejores datos científicos, y a su vez, los Estados miembros deben adoptar las medidas que sean necesarias para recopilar datos de la PMR que enviarán a la Comisión con el fin de desarrollar una base de datos común que contenga datos exhaustivos y fiables, a disposición de la comunidad científica para controlar y evaluar el estado de los recursos pesqueros.

\section{El fomento de la participación en la gestión de las pesquerías recreativas}


Atendiendo a los estudios científicos que califican la pesca marítima recreativa como una actividad pesquera extractiva -independientemente de las connotaciones lúdicas, deportivas o turísticas-, el sector recreativo debe configurarse como legítimo usuario de los recursos pesqueros y ser tenido en cuenta en la conformación de la política pesquera y medioambiental de la Unión ${ }^{71}$.

El impulso hacia la participación del sector recreativo en la política pesquera europea surgió con el Reglamento 2371/2002 de la PPC ya derogado. Entre sus objetivos figuraba el compromiso de fomentar una amplia participación de todos los agentes interesados en cada una de las fases de elaboración de la política pesquera. Aunque este loable propósito abrió la puerta a la PMR gracias al artículo 2.c), las instituciones comunitarias han prestado escasa o nula atención a esta posibilidad, a pesar de los requerimientos de la Comisión: "la política pesquera común tiene que adaptarse a un sector que abarca desde la pesca recreativa privada en un extremo, hasta compañías cotizadas en varios millones de euros en el otro, y que engloba toda la cadena de mercado, desde el punto de captura hasta la venta final, pasando por el desembarque, el transporte, el procesado y la distribución"72. En el mismo sentido se pronunció el Parlamento Europeo, destacando el importante papel de la PMR en el conjunto de la pesca europea y mostrando su preocupación ante la creciente tensión entre los pescadores de bajura y la pesca recreativa. ${ }^{73}$ Sin embargo, la cooperación entre los Estados miembros - por medio de los Consejos consultivos- no se intensificó hasta la aprobación del Reglamento 1380/2013 sobre la política pesquera común, con el fin de fijar medidas de conservación regionalizadas y haciendo participes a todos los agentes interesados ${ }^{74}$.

\footnotetext{
${ }^{71}$ Tony J. Pitcher, Chuck Hollingworth (Eds.). Recreational Fisheries: Ecological, Economic and Social Evaluation, Oxford, UK, Blackwell Science Ltd. 2002, p. 271.

72 Comisión Europea, The Common Fisheries Policy: A User's Guide, Luxembourg: Office for Official Publications of the European Communities, 2009, 40 p.

${ }^{73}$ Parlamento Europeo, Workshop- Rights Based Management in Fisheries, 2007, 79 p.

${ }^{74}$ Artículo 43 del Reglamento 1380/2013 de la PPC.
} 
Originariamente, los Consejos consultivos, regulados mediante la Decisión del Consejo 2004/585/CE, de 19 de julio de 2004 ${ }^{75}$, vieron mejorada su composición con la integración de "otros grupos interesados", junto a los representantes del sector pesquero. Con esta estructura se pretendía garantizar una representación equilibrada de todas las partes legítimas interesadas, tales como las organizaciones y grupos de protección del medio ambiente, acuicultores, consumidores, e implícitamente, los pescadores de pesca recreativa 0 deportiva. ${ }^{76}$

En consecuencia, la reinante PPC refuerza la estructura institucional de los Consejos, pero su naturaleza meramente consultiva queda limitada en cuanto a la efectiva toma en consideración de sus dictámenes, especialmente en el caso sean unánimes. Según el artículo 44 de la PPC, entre las funciones de los Consejos, además de emitir dictámenes, está la de elaborar recomendaciones y sugerencias, así como informar a la Comisión y a los Estados interesados de cuestiones relacionadas con la gestión de la pesca; aparte, de contribuir en estrecha cooperación con los científicos, a la recogida, suministro y análisis de los datos necesarios para la elaboración de medidas de conservación. En contrapartida, la Comisión y, en su caso, el Estado miembro interesado, están obligados a responder a las cuestiones planteadas por los Consejos. Obviamente, la participación del sector recreativo en estos órganos denota un avance de gran calado para su reconocimiento como agente interesado en la construcción y aplicación de la PPC ${ }^{77}$.

\footnotetext{
75 Decisión del Consejo de 19 de julio de 2004 por la que se crean consejos consultivos regionales en virtud de la política pesquera común, publicada en el Diario Oficial de la Unión Europea, L 256, de 3 de agosto de 2004, p.17-22.

${ }^{76}$ En la composición de los Consejos consultivos, el $60 \%$ de los puestos de la asamblea general y del comité ejecutivo se asignan a representantes de los pescadores y representantes de los sectores de transformación y comercialización, mientras que el $40 \%$ restante corresponde a los representantes de otros grupos de interés afectados por la Política Pesquera Común, como por ejemplo el sector recreativo. De los once consejos consultivos existentes, el sector recreativo español participa activamente en los relativos al Mediterráneo, Atlántico sur y el de la flota de larga distancia en aguas no comunitarias, <https://acpr.cat/wp-content/uploads/2019/11/6Presencia-en-foros-pesqueros-internacionales-2010.pdf > [Última consulta, 31 de mayo de 2021].

77 Un organismo de interés para el sector recreativo es el que configura una Organización de gestión de la pesca con caña (Angling management organization, AMO). Las AMO gozan del derecho exclusivo de decisión sobre cómo utilizar su parte de cuota recreativa, en Jon G. Sutinen, Robert J. Johnston, "Angling management organizations: integrating the recreational sector into fishery management", Marine Policy, no 27, 2003, p. 471.
} 


\section{CONCLUSIONES}

Durante el proceso de elaboración de la actual Política Pesquera Común, algunas voces plantearon el reconocimiento de la pesca marítima recreativa como grupo de interés con derecho propio en el marco común de la pesca. A pesar de los beneficios y las enormes potencialidades socioeconómicas que puede aportar el sector recreativo, el texto final del Reglamento 1380/2013 sobre la Política Pesquera Común, se hizo eco de esta problemática de manera insuficiente. Por ello, se han analizado las normas comunitarias cuya aplicación afecta a la pesca marítima de recreo, destacando la importancia de mejorar los mecanismos de recogida y tratamiento de los datos relativos a la pesca marítima recreativa y de aplicación efectiva del régimen de control.

Con el objeto de implementar estrategias de gestión inclusivas que permitan alcanzar la sostenibilidad de la pesca europea a largo plazo, es necesario admitir que cualquier pesquería tiene el potencial de producir consecuencias negativas sobre las poblaciones de peces y los hábitats de los que forman parte. Tanto la pesca recreativa como la comercial pueden contribuir a la disminución de las poblaciones de peces, especialmente si se dan en el marco de la pesca ilegal.

Al mismo tiempo, en línea con las metas previstas en la Política Marítima Integrada, en la Estrategia Marina de la Unión y en el Fondo Europeo Marítimo y de la Pesca -en cuanto al fomento de la diversificación pesquera y la ordenación sostenible de todos los usos del mar a nivel regional- este trabajo pretende poner el acento en la necesidad de avanzar, desde el punto de vista jurídico, en la elaboración de una regulación común sobre determinados aspectos de la pesca marítima de recreo teniendo en cuenta las particularidades de cada zona marítima. La fórmula para llevar a cabo este ambicioso objetivo de cara a la nueva PPC, podría materializarse en el seno de los futuros planes de gestión; o bien, mediante la aprobación de una serie de Directivas en la materia. De ahí, la importancia de aplicar los principios de buena gobernanza europea de la pesca, basados, entre otros principios, en el enfoque regionalizado a escala de cuenca marítima y en la participación de todos los agentes interesados, especialmente la del sector recreativo de la pesca. 


\section{BIBLIOGRAFÍA}

Abbott, Joshua K., "Fighting over a Red Herring: The Role of Economics in Recreational- Commercial Allocation Disputes". Marine resource economics, 30, 2015.

Arana García, Estanislao, Navarro Ortega, Asensio, y Sanz Larruga, Francisco Javier, (Dirs.): La ordenación jurídica del medio marino en España: estudios sobre la Ley 41/2010, de protección del medio marino, Civitas-Thomson-Reuters, Cizur Menor, 2012.

Arlinghaus, Robert, Abbott, Joshua K., Fenichel, Eli P., et al., "Governing the recreational dimension of global fisheries", en PNAS, vol. 116, nำ12, 2019.

Arroyo Martínez, Ignacio, Compendio de Derecho Marítimo, 3aㅡ Ed, Tecnos, Madrid, 2009.

Barange, Manuel, Bahri, Tarûb, Beveridge, Malcolm C.M., Cochrane, Kevern L., Funge-Smith, Simon, and Poulain, Florence, "Impacts of Climate Change on Fisheries and Aquaculture: Synthesis of currrent knowledge, adaptation and mitigation options", FAO Fish, Rome, 2018.

Boudouresque, Charles, Bernard, Guillaume, Pergent, Gerard, Shili, Abdessalem, Verlaque, Marc, "Regression of Mediterranean seagrasses caused by natural processes and anthropogenic disturbances and stress: a critical review". Botanica Marina 52, 2009.

Carboneras, Carles, Las aves marinas en España. Interacciones con artes de pesca. Casos prácticos, en Curso sobre Conservación y Gestión de la Biodiversidad Marina en España, Ministerio de Medio Ambiente y Medio Rural y Marino, Vigo, 22-26, septiembre 2008

Comisión Europea, Libro Verde de reforma de la Política Pesquera Común, 2009.

Comisión Europea, Resumen de la consulta sobre la reforma de la Política Pesquera Común, Documento de trabajo de los servicios de la Comisión, SEC (2010) 428 final, 2010. 
Comisión Europea, The Common Fisheries Policy: A User's Guide, Luxembourg: Office for Official Publications of the European Communities, 2009.

Consejo Económico y Social, Informe CES 01/2013, La reforma de la Política Pesquera Común, Madrid, 2013.

DiStefano, Robert J., Litvan, Mary E., Horner, Paul T., "The Bait Industry as a Potential Vector for Alien Crayfish Introductions: Problem Recognition by Fisheries Agencies and a Missouri Evaluation". Fisheries, № 34(12), 2009.

European Commission. New proposal will tackle marine litter and "ghost fishing", 2018.

FAO, Recreational fisheries. Technical Guidelines for Responsible Fisheries. No. 13. Rome, 2012.

Font, Toni, Lloret, Josep, Análisis de la pesca de recreo en las 10 Áreas LIC del proyecto LIFE+INDEMARES, Universidad de Girona - Ministerio de Agricultura, Alimentación y Medio Ambiente - Fundación Biodiversidad, 2013.

Font, Toni, Lloret, Josep, Piante, Catherine, Recreational Fishing Within Marine Protected Areas in the Mediterranean Marine Protected Areas in the Mediterranean. Technical Report, MedPAN North Project, WWF France, 2012.

Francour, Patrice, Ganteaume, Anne, and Poulain, Maxime, "Effects of boat anchoring in Posidonia oceanica seagrass beds in the Port-Cros National Park (NW Mediterranean Sea)". Aquatic Conservation: Marine and Freshwater Ecosystems, ํㅜ 9,1999.

GFCM. Report of the first meeting of the Working Group on Small-Scale and Recreational Fisheries (WGSSF). FAO, Rome, 2017.

Giménez Casalduero, María., "Las áreas marinas protegidas: nuevas perspectivas a la luz de la Ley 42/2007, del patrimonio natural y de la biodiversidad", Revista Catalana de Dret Ambiental, Vol. 1, n.․ 1, 2010.

Gómez, Silvia, Carreño, Arnau, Sánchez, Elvira, Martínez, Esther, y Lloret, Josep, Safeguarding Marine Protected Areas in the growing Mediterranean Blue Economy. Recommendations for Recreational Fisheries. PHAROS4 MPAs project, 2019. 
Gordoa, Ana (Coord.), SFITUM Project: Sport Fishing: an informative and economic alternative for Tuna fishing in the Mediterranean, DG Fish. 2003.

Hyder,, Kieran, Weltersbach, Marc, Armstrong, Mike, et al., "Recreational Sea fishing in Europe in a global context. Participation rates, fishing effort, expenditure, and implications for monitoring and assessment". Fish Fish. 2018.

ICES, Report of the Working Group on Recreational Fisheries Surveys (WGRFS), ICES CM 2013/ACOM:23, 2013.

ICES. Report of the Planning Group on Recreational Fisheries (PGRFS), Bergen, Norway. ICES CM 2010/ACOM:34. 2010.

León, Víctor M., Bellido, José M., (Eds.). "Mar Menor: una laguna singular y sensible. Evaluación científica de su estado". Temas de Oceanografía, Instituto Español de Oceanografía, Ministerio de Economía y Competitividad. Madrid, oo 9, 2016.

Lloret, Josep, Riera, Victoria, "Evolution of a Mediterranean Coastal Zone: Human Impacts on the Marine Environment of Cape Creus". Env. Manag, n‥ 42, 2008.

Lozano Cutanda Blanca, "Real Decreto 363/2017, de 8 de abril, la ordenación de los distintos usos y de las actividades económicas en el espacio marítimo", Diario La Ley, Número 8999, 2017.

Menéndez Rexach, Ángel, "La ordenación del espacio marítimo", en Núñez Lozano María del Carmen, (Dir.), Estudios Jurídicos sobre el litoral, Tirant lo Blanch, Valencia, 2016.

Ortiz García, Mercedes, "Las áreas marinas protegidas: mayor importancia por el cambio climático", Observatorio de Políticas Ambientales 2020, en GarcíaÁlvarez García, Gerardo, Jordano Fraga, Jesús, Lozano Cutanda, Blanca, Nogueira López, Alba, (Coord.), 2020.

Parlamento Europeo, Resolución de 12 de junio de 2018, sobre la situación de la pesca recreativa en la Unión, (2017/2120 (INI)), 2018.

Parlamento Europeo, Workshop- Rights Based Management in Fisheries, 2007. 
Pita, Pablo, Alós, Josep, Antelo, Manel, et al., "Estado del arte de la investigación sobre pesca marítima recreativa en España", en Pita, Pablo y Villasante, Sebastián, (Eds.): Informe técnico del Proyecto SICORE. 2018, Santiago de Compostela, España.

Pitcher, Tony J., Hollingworth, Chuck., (Eds.). Recreational Fisheries: Ecological, Economic and Social Evaluation. Oxford, UK, Blackwell Science Ltd. 2002.

Sanz Larruga, Francisco Javier, "La nueva ordenación del espacio marítimo: análisis del Real Decreto 363/2017, de 8 de abril”, Práctica Urbanística ํㅜ150, Editorial Wolters Kluwer, 2018.

Soro Mateo, Blanca, Hacia una gobernanza de las áreas marinas protegidas: estado de la cuestión y algunos retos a vencer, Administración de Andalucía: revista andaluza de administración pública, №. 104, 2019.

Suárez de Vivero, José Luis, Rodríguez Mateos, Juan Carlos, "The Spanish approach to marine spatial planning. Marine Strategy Framework Directive vs. EU Integrated Maritime Policy", Marine Policy, n.ํ 36, 2012.

Sutinen, Jon G., Johnston, Robert J., "Angling management organizations: integrating the recreational sector into fishery management", Marine Policy, $\mathrm{n}^{\circ}$ 27, 2003.

TRAGSATEC, Estudio del impacto socioeconómico de la pesca recreativa en el Mediterráneo Español, Secretaría General de Pesca Marítima, Ministerio de Agricultura, Pesca y Alimentación, Madrid, versión actualizada 2010.

Voyer, Michelle, Barclay, Kate, Mcilgorm, Alistair, Mazur, Nicole, "Connections or conflict? A social and economic analysis of the interconnections between the professional fishing industry, recreational fishing and marine tourism in coastal communities in NSW, Australia", Marine Policy, 76: 2017. 